\title{
"PREFIRO APRENDER DO QUE DECORAR": A CULTURA AUDIOVISUAL E A CRÍTICA DOS ALUNOS À REALIDADE ESCOLAR
}

\author{
Dimitri Barros GUANDALIM ${ }^{1}$ \\ Maria Angélica C. PARAIZO ${ }^{2}$ \\ Paulo Eduardo TEIXEIRA ${ }^{3}$
}

RESUMO: O presente trabalho visa trazer à tona uma discussão em torno da viabilidade das metodologias tradicionais de ensino num contexto social predominantemente tecnológico e imagético. A partir de projetos realizados na disciplina de História, numa escola estadual através do Núcleo de Ensino da Unesp de Marília, e a aplicação de questionários que visavam mapear aspectos da cultura audiovisual dos alunos conjuntamente com suas percepções acerca da realidade cotidiana na escola, tornou-se evidente a perspectiva crítica que os alunos do Ensino Médio encaravam a estrutura escolar. Com o uso do software SPSS, foram analisadas as questões de caráter quantitativo, possibilitando uma crítica às metodologias de ensino utilizadas pelos professores, ao passo que o uso de imagens revelou-se como uma proposta capaz de estimular uma educação pautada na interação e no diálogo, aproximando-se da realidade sócio-cultural dos educandos.

PALAVRAS-CHAVE: Cultura audiovisual. Estudantes. Ensino médio. Metodologia de ensino. Marília (SP).

\section{Introdução}

Esta comunicação visa descrever alguns resultados de uma pesquisa com relação à metodologia de ensino voltada para o Ensino Médio, sobretudo, com a criação de material didático audiovisual a partir de uma abordagem temática de caráter históricosociológico. Através do Núcleo de Ensino da Unesp de Marília como atividade de extensão na Escola Estadual Amílcare Mattei, mais de 353 alunos tiveram a oportunidade de participar de aulas de História sob a metodologia do uso de imagens por meio dos projetos “O ensino da História Política do Brasil com o uso de imagens na sala de aula” (2007-2008) e “A imagem didática: uma abordagem Histórico-Sociológica da escravidão no Brasil” (2009).

\footnotetext{
${ }^{1}$ Bolsista do Núcleo de Ensino - UNESP - Universidade Estadual Paulista. Faculdade de Filosofia e Ciências - Departamento de Ciências Políticas e Econômicas. Marília - SP - Brasil. 17525-900 dimitribguandalim@hotmail.com.

${ }^{2}$ Bolsista do Núcleo de Ensino - UNESP - Universidade Estadual Paulista. Faculdade de Filosofia e Ciências - Departamento de Ciências Políticas e Econômicas. Marília - SP - Brasil. 17525-900 angelica.paraizo@yahoo.com.br.

${ }^{3}$ Coordenador Projeto do Núcleo de Ensino - UNESP - Universidade Estadual Paulista. Faculdade de Filosofia e Ciências - Departamento de Ciências Políticas e Econômicas. Marília - SP - Brasil. 17525900 - ptmarilia@gmail.com.
} 
Essencialmente no primeiro semestre de cada ano foram criados os materiais temáticos audiovisuais voltados para as aulas da disciplina de História, com a participação direta de todos os bolsistas e voluntários sob a orientação do coordenador dos projetos, sendo que nesta etapa a ação era desenvolvida na Universidade. No segundo semestre, o grupo ministrava as aulas de História, sempre com a presença da professora responsável, mas com uma agenda previamente definida, dando a oportunidade dos graduandos do Curso de Ciências Sociais terem a experiência de lecionarem para classes de alunos que cursavam o Ensino Médio. E ao final dessa etapa, ocorria aquilo que considerávamos muito importante, uma avaliação sobre o impacto do projeto na vida acadêmica desses alunos. O questionário não era obrigatório, e os alunos respondiam sem ter a necessidade de se identificarem pelo nome, dando liberdade total para responderem aquilo que quisessem, por essa razão, o número mínimo estimado de participantes foi de 353 alunos ao longo dos três anos, no entanto podemos presumir que o total de alunos que participaram efetivamente chegou a 400 pessoas.

O questionário possuía perguntas com características qualitativas e quantitativas para avaliar vários aspectos, e mapear a cultura audiovisual dos mesmos, o uso dos recursos audiovisuais na escola e a percepção dos educandos sobre os recursos metodológicos utilizados durante o projeto, além de questões sobre a postura dos discentes do Curso de Ciências Sociais que ministravam as aulas. Todos os questionários foram importados para o programa SPSS, que serviu de ferramenta para a análise quantitativa. Portanto, nosso objetivo com esta comunicação é apresentar alguns resultados desta pesquisa, sobretudo no que tange aos aspectos da cultura audiovisual dos alunos da E. E. Prof. Amílcare Mattei, de Marília, proporcionando uma reflexão sobre o processo de ensino e aprendizagem no contexto de uma sociedade midiática.

\section{A cultura audiovisual dos educandos}

No ano de 2007 o projeto atingiu 23 alunos do Ensino Fundamental da $7^{\mathrm{a}}$ A, e como o projeto era voltado principalmente para o Ensino Médio, participaram 27 alunos do $2^{\circ}$ B, 21 do $3^{\circ}$ A e 23 do $3^{\circ}$ B, totalizando 94 alunos. Em 2008 e 2009, consideramos focar nossa atenção especialmente sobre os alunos do Ensino Médio, uma vez que o sucesso do mesmo diante da Direção da Escola parceira levou-a a solicitar a inclusão de mais classes de alunos, de modo que nossas intervenções ocorriam normalmente entre os meses de setembro e outubro (dois meses consecutivos e durante as aulas duplas). 
Assim, em 2008 participaram do projeto 27 alunos do $1^{\circ} \mathrm{E}, 20$ do $1^{\circ} \mathrm{F}, 23$ do $2^{\circ} \mathrm{A}, 15$ do $2^{\circ} \mathrm{C}, 18$ do $3^{\circ} \mathrm{A}, 11$ do $3^{\circ} \mathrm{B}, 25$ do $3^{\circ} \mathrm{C}$, no total de 139 alunos. Esses números indicam que muitos alunos não responderam aos questionários, ou porque não vieram na aula no dia da aplicação do mesmo, ou simplesmente porque não quiseram responder. Em 2009, tivemos a participação total de 120 alunos, sendo que os temas tratados ficaram restritos a todo o $2^{\circ}$ colegial, sendo 25 , no A, 11 no B, 28 no C e D, além de 16 no $3^{\circ} \mathrm{A}$ e 12 do $3^{\circ} \mathrm{B}$. Portanto, consideramos que essa amostragem foi satisfatória e representativa para fazer as análises preliminares dos projetos, mostrando que também entre os alunos que responderam houve um equilíbrio entre os sexos, ou seja, dentre aqueles que declararam essa informação, 154 (43,6\%) eram do sexo masculino, enquanto que as mulheres corresponderam a 158 (44,8\%).

Tabela 1 - Aparelhos que os alunos possuem em casa

\begin{tabular}{|c|c|c|c|c|c|}
\hline Tipos de Aparelho & $\begin{array}{c}7^{\mathrm{a}} \\
\text { série }\end{array}$ & $\begin{array}{c}1^{0} \\
\text { colegial }\end{array}$ & $\begin{array}{c}2^{\mathbf{0}} \\
\text { colegial }\end{array}$ & $\begin{array}{c}3^{0} \\
\text { colegial }\end{array}$ & Total \\
\hline Aparelho de som & 23 & 76 & 134 & 97 & 330 \\
\hline Televisão & 22 & 87 & 139 & 100 & 348 \\
\hline Computador & 11 & 49 & 96 & 69 & 225 \\
\hline Computador com acesso à internet & 11 & 53 & 99 & 75 & 238 \\
\hline Videocassete e/ou DVD & 20 & 84 & 137 & 94 & 335 \\
\hline Máquina fotográfica analógica & 4 & 25 & 55 & 34 & 118 \\
\hline Máquina fotográfica digital & 7 & 41 & 86 & 60 & 194 \\
\hline Filmadora & 7 & 12 & 41 & 29 & 89 \\
\hline Celular & 19 & 71 & 120 & 84 & 294 \\
\hline Celular com câmera & 14 & 69 & 117 & 78 & 278 \\
\hline MP3 player e/ou Ipod & 15 & 65 & 109 & 64 & 253 \\
\hline
\end{tabular}

Fonte: elaboração própria.

Da análise da Tabela 1 constatamos que o universo material que cerca os alunos demonstra a importância da comunicação audiovisual dos mesmos no contexto dos relacionamentos familiares e de amizade. Do total de alunos que responderam a estas perguntas, ou seja, dos 353, notamos a quase totalidade da presença da TV na casa, uma elevada porcentagem daqueles que possuem aparelho de som e videocassete e/ou DVD. Além disso, notamos uma grande quantidade de celulares e/ou celulares com câmera, além do MP3. Mesmo a presença da filmadora (25\%) entre os alunos demonstra a proximidade dos mesmos com o mundo das tecnologias da comunicação. Por outro lado, ao vermos a presença do computador e o uso da "internet”, demonstra a inserção dessas pessoas no mundo virtual, que as remete a criação de redes sociais que muitas 
vezes as colocam em contato com outras pessoas, outras realidades, gerando a criação de um conhecimento e de uma vivência que ultrapassa os muros da casa, da vizinhança, do bairro, da cidade, do estado e do Brasil!

Diante disso, qual a expectativa do aluno que vive neste mundo midiático, envolto pelas tecnologias da comunicação virtual diante da escola? Está a escola oferecendo algo semelhante a esse aluno, ou seja, a escola está usando os meios conhecidos pelos alunos para educá-los para a sociedade, ou simplesmente está oferecendo aquilo que era oferecido como o melhor para uma educação pautada tão somente na escrita, nos livros e cadernos?

Tabela 2 - Alunos que em casa alguém assina algum tipo de Jornal e/ou Revista

\begin{tabular}{|c|c|c|c|c|c|}
\hline Assinam Jornal/Revista & $\begin{array}{c}\mathbf{7}^{\mathbf{a}} \\
\text { série }\end{array}$ & $\begin{array}{c}\mathbf{1}^{\mathbf{o}} \\
\text { colegial }\end{array}$ & $\begin{array}{c}\mathbf{2}^{\mathbf{o}} \\
\text { colegial }\end{array}$ & $\begin{array}{c}\mathbf{3}^{\mathbf{o}} \\
\text { colegial }\end{array}$ & Total \\
\hline Sim & 6 & 19 & 38 & 29 & 92 \\
\hline Não & 16 & 68 & 104 & 71 & 259 \\
\hline
\end{tabular}

Obs.: Dois alunos não responderam a esta questão.

Fonte: Elaboração própria.

A Tabela 2 mostra outra realidade na vida desses alunos, que é a de não terem, em sua maioria, acesso aos meios de comunicação escritos como jornais e revistas, ou seja, apenas $26 \%$ dos alunos disseram ter condições de realizarem a compra ou assinatura de algum tipo de mídia impressa. Questionados sobre os lugares em que faziam suas leituras, 48,7\% (172 alunos) disseram que as faziam na escola, enquanto a casa foi o segundo lugar em que havia condições para isso (26\%, ou 92 alunos). No entanto, 17 alunos disseram que liam nos consultórios, outros 16 disseram ler nas bancas de jornal, 11 “no vizinho”, e apenas 7 liam nas bibliotecas!

Tais resultados apontam para uma mudança de comportamento coletivo, e ao mesmo tempo demonstra a escassez de recursos financeiros para investir na compra de jornais/revistas, não obstante, conforme observamos pela Tabela 1 conseguiram priorizar a aquisição de produtos eletroeletrônicos que fornecem informações por outras formas. Procurando avaliar o grau de freqüência com que esses alunos assistiam filmes comprados/locados notamos que a maior parte deles (118 alunos - 33,4\%) respondeu que faziam isso entre 2 a 3 vezes por semana, enquanto que $98(27,7 \%)$ assistiam a filmes dessa maneira apenas uma vez por semana, e 79 alunos (22,4\%) o faziam apenas 
uma vez por mês. A freqüência ao cinema revelou que a maioria deles (222 alunos 62,8\%) fazia isso apenas uma vez ao mês, enquanto que 272 alunos responderam que assistiam a algum programa de TV “todos os dias da semana”. Essa avaliação possibilitou perceber que para ir ao cinema ou mesmo comprar/locar filmes os alunos conseguem recursos, bem mais que para adquirirem livros, revistas ou jornais. Embora deva ser considerada a compra de produtos “piratas”, que o passeio ao cinema ocorra em dias de "promoção", ainda assim a regularidade desses eventos demonstra a atração que os veículos de comunicação audiovisual impõem a estes jovens.

Em contraste, o que a escola está oferecendo? Livros didáticos, lousas, muito giz, e poucos recursos audiovisuais. Por quê? Na Escola Amílcare Mattei encontramos dificuldades no início da implantação do projeto, ou seja, em 2007, uma vez que havia apenas uma sala de vídeo, e mesmo assim o DVD não estava funcionando, tendo que levarmos esse equipamento de casa durante todas as aulas. Em 2008 e 2009 as aulas passaram a ser realizadas na sala que estavam os computadores, mas que pouco era utilizada, segundo os alunos. Mas voltemos a questão, porque as escolas não estão equipadas e preparadas para educar os jovens a partir de outros objetos de aprendizagem?

Indagados os alunos sobre o projeto que usou a imagem na sala de aula como interlocutora desse diálogo que foi sendo estabelecido entre nós, educadores, e os alunos, recebemos algumas respostas como esta: "Eu gostei de sair um pouco da rotina chata de ficar na sala de aula, trabalhando só com a imagem de uma lousa cheia. Os vídeos nos mostram um pouco mais da realidade” ( $2^{\circ}$ Colegial $)$.

Nota-se por esta resposta que há uma crítica ao espaço escolar, e que "sair" representou algo significativo para este jovem. Deixar a sala, a lousa, o giz, e principalmente o professor que detém o saber, e buscá-lo no vídeo, foi uma experiência “nova” dentro daquele espaço, mas não estritamente "nova” para sua vida. A lousa, ou “quadro-negro”, na visão de Wittich e Schuller (1964, p.56) era considerada parte integrante da sala de aula, “a tal ponto que chegou a ser sinônimo de educação”. Na visão dos autores, o uso da lousa deveria ocorrer principalmente quando surgissem discussões que exigiriam a exposição de ideias onde a visualização ajudaria para uma melhor compreensão. Nesse sentido, o que notamos é uma subversão do uso desse instrumento voltado ao processo de ensino e aprendizagem, tornando-o um sinônimo de uma educação “chata”! 
Outro aluno, descrevendo suas impressões sobre o uso da imagem na sala de aula em 2007, nos disse que: “Como as aulas aconteciam às sextas-feiras nas duas últimas aulas eu não ia querer copiar. E usando a TV a sala se concentra mais do que olhando para uma lousa” ( $3^{\circ}$ Colegial).

Olhar para a TV, para o vídeo, foi uma experiência diferente na sala de aula para muitos alunos, pois essa prática estava limitada ao ambiente externo, a casa, ao shopping, enquanto que a escola mantinha-se isolada diante do mundo das Tecnologias de Informação e Comunicação (TIC).

Na perspectiva apontada pelos alunos citados, o uso da televisão abriu possibilidades na medida em que os mesmos conseguiram se distanciar da sala de aula, já que estava caracterizada como um ambiente de tédio e monotonia. A imagem da lousa cheia, conjuntamente com a configuração do ambiente de aula e a relação formal entre professor-aluno, certamente expressaria um ambiente em decadência, desestimulante à construção coletiva do conhecimento. Assim, além da carência de TICs na escola analisada, devemos ponderar quanto ao uso desses instrumentos de comunicação, uma vez que geram a necessidade de rever a relação professor-aluno, pois o formato tradicional da sala de aula com lousa e giz, pressupõe lugares de saberes, saberes que valorizam a forma e o conteúdo de um dado tema ou objeto.

Sob a ótica de Foucault (1986), a vivência de um sujeito submetido a um sistema educacional que privilegiou o conteúdo, justamente porque estava pautado sob a ótica da dominação e controle social, demonstra a vinculação histórica entre os saberes e o poder disciplinador, mecanismo pautado no "aparelho de escrita", que impõe a possibilidade de

[...] constituição do indivíduo como objeto descritível, analisável, [...] para mantê-lo em seus traços singulares, em sua evolução particular, em suas aptidões ou capacidades próprias, sob o controle de um saber permanente; e por outro lado a constituição de um sistema comparativo que permite a medida de fenômenos globais, a descrição de grupos, a caracterização de fatos coletivos, a estimativa dos desvios dos indivíduos entre si, sua distribuição numa população (FOUCAULT, 1986, p.169).

Na fala desses mesmos alunos, fica evidente também que o uso de vídeos, imagens e a televisão propiciam condições para que a relação de ensino-aprendizagem possa se estabelecer em um contexto de maior diálogo entre os alunos, os professores e os professores e alunos, conforme a afirmação de um aluno do $2^{\circ}$ Colegial, que disse: 
“Eu prestava mais atenção na aula para ter uma maior participação no debate”. Ao estimular o debate, a intenção era propiciar condições para a quebra de uma relação rígida de poder entre os educadores e o educando, de modo que o educando não procure absorver o conteúdo de maneira passiva, pois o conhecimento histórico “é visto como uma verdade absoluta, homogeneizadora” (ZAMBONI, 1998, p.89).

Com as TICs uma relação professor-aluno diferente se estabelece, uma vez que muitas vezes o aluno "domina” mais conhecimento do que o "professor" em relação ao uso desses canais de comunicação que são essencialmente visuais. Por isso, durante as atuações junto aos alunos, a metodologia de ensino acolhida por nós previa essa mudança de comportamento, procurando valorizar o "saber” dos alunos envolvidos no processo de ensino e aprendizagem.

Em uma pergunta feita aos alunos "quanto ao fato de não fazermos uso da lousa” durante todas as aulas, 211 (60\%) assinalaram que isso foi "bom, pois aumenta a capacidade de memorização pelo uso da TV”, enquanto outros 73 alunos (20,7\%) responderam à mesma pergunta assinalando que foi "bom, pois não tem que escrever nada no caderno”. Essas respostas apontam para uma forma diferente de aprender, de olhar, a partir de outra base material que não o livro, o caderno e a lousa. Em complemento a essa questão, um aluno respondeu: "Essa história de ficar tendo que copiar tudo da lousa, enche o saco, desanima. Através das imagens, os alunos se interessam mais e não cansam” ( $3^{\circ}$ Colegial).

\section{Uma problemática: a educação formalista e um novo contexto para a educação}

Podemos notar que as palavras dos alunos citados acima remetem a uma crítica ao método de ensino que se caracteriza, muitas vezes, pela falta de diálogo e interação social no processo de ensino-aprendizagem, ainda marcado por relações de caráter formal e autoritário.

Entre as diferentes respostas, questões como a falta de emotividade nas relações de ensino ficaram patentes. É necessário frisar que relações formalizadas são expressões de uma educação burocrática, aquela que tanto os alunos criticam. A música enquanto recurso metodológico foi muito apreciado, pois na visão de um aluno do $3^{\circ}$ Colegial "as músicas combinam mais para criticar ou expressar idéias e emoções.”

As relações e a educação de caráter formalista, para pensar nos termos do sociólogo Simmel (2006), têm uma forte tendência a estimular a perda de atratividade 
por parte dos agentes que atuam em seu interior, ou seja, tal modelo educacional necessariamente propicia uma perda de sentido para a comunidade escolar; deste modo, acaba por se tornar nada mais do que uma obrigação a ser cumprida, no interior de instituições fortemente burocratizadas e por extensão, rotinizadas. A perspectiva do aluno adquire uma dimensão banalizada, na medida em que os educadores se inserem num processo onde, por regra, a apatia, a indiferença e a falta de inovação acabam por se cristalizarem como realidades frequentes e não raro encaradas como estáticas.

Por outro lado, devido às novas subjetividades que emergem num contexto social marcado pela interatividade e intersubjetividade crescentes, a comunicação assume uma centralidade numa perspectiva de globalização. A educação formalista, por sua vez, passa por um processo de reestruturação, onde tanto as políticas públicas quanto a comunidade escolar em consonância com diversos setores da sociedade civil demonstram a viabilidade de se pensar outro modelo educacional e outros métodos de ensino. O Multiculturalismo e as diversas expressões identitárias que visam o reconhecimento intersubjetivo constituem-se como temas a serem discutidos em sala de aula.

O uso de diferentes recursos pedagógicos que visam à diversificação das linguagens na prática do ensino escolar tornou-se um debate experimentado tanto em âmbitos acadêmicos quanto nas redes públicas de ensino. No interior dessas últimas, os alunos, enquanto agentes sociais dotados de criticidade, propiciaram contribuições para quebrar os paradigmas tradicionalistas, através de uma reflexão que problematiza os diversos âmbitos educacionais.

Para romper com a idéia de transmissão passiva de conteúdo, ao se utilizar da imagens, o educador deve ressaltar a idéia de representação da realidade, socialmente e culturalmente construída, uma vez que as "imagens e discursos sobre o real não são exatamente o real ou, em outras palavras, não são expressões literais da realidade”, mas sim suas representações (PESAVENTO, 1995, p.15).

Cotidianamente, tanto professores, quanto alunos encontram-se imersos em uma realidade permeada por signos imagéticos das mais variadas formas, sendo estes fotográficos ou cinematográficos. Deste modo, a manipulação e a interpretação de imagens são necessidades recorrentes em nossa sociedade (BITTENCOURT, 1998). Nessa perspectiva, o aprendizado pautado na leitura de imagens revela sua fundamental importância, e contribui de maneira decisiva para um novo tipo de construção de conhecimento, onde o professor não é apenas um transmissor de conteúdo para as 
cabeças vazias dos alunos, mas ambos são agentes necessários e ativos num processo interativo e dialógico, a exemplo da metodologia inaugurada pelo pedagogo Paulo Freire (2005).

\title{
Considerações finais
}

Na contemporaneidade, as relações sociais entre os sujeitos e o mundo social se tornaram cada vez mais mediadas e significadas através das imagens, sejam elas fotográficas, cinematográficas ou digitais. As gerações de alunos que estão se desenvolvendo no mundo predominantemente tecnológico e imagético evidenciam demandas onde os modelos pedagógicos mais tradicionais denunciam inúmeras debilidades. A inclusão de artefatos tecnológicos, ou Tecnologias de Informação e Comunicação (TIC) como são chamados hoje em dia, não garante o sucesso do aprendizado conforme expôs CYSNEIROS (1999), e muitas vezes não passam de uma “inovação conservadora em educação”.

\section{"I PREFER LEARN THAN DECORATE": AUDIOVISUAL CULTURE AND THE CRITICISM OF THE SCHOOL REALITY}

\begin{abstract}
The present work aims to bring up a discussion around the viability of traditional teaching methods in a world predominantly technological and imagetic. A project conducted in the discipline of history, in a state school through the Núcleo de Ensino (Center for Teaching) UNESP Marília, we applied questionnaires that aimed to map aspects of the visual culture of the students, and their perception of everyday reality in school. Using the SPSS software, the issues of quantitative trait were analyzed, providing a critique of the teaching methods used by teachers, whereas the use of images has been revealed as a proposal capable of stimulating an education based on interaction and dialogue, approaching the socio-cultural reality of learners.
\end{abstract}

KEYWORDS: Audiovisual culture. Students. High school. Teaching methodology. Marília (SP).

\section{REFERÊNCIAS}

BITTENCOURT, C. (Org.). O saber histórico na sala de aula. São Paulo: Contexto, 1998. 
CYSNEIROS, P. G. Novas tecnologias na sala de aula: melhoria do ensino ou inovação conservadora? Informática Educativa, Bogotá, CO, v.12, n.1, p.11-24, 1999.

FOUCAULT, M. Vigiar e punir: história da violência nas prisões. 4.ed. Petrópolis: Vozes, 1986.

FREIRE, P. Pedagogia do Oprimido. 43.ed. Rio de Janeiro: Paz e Terra, 2005.

PESAVENTO, S. J. Em busca de uma outra História: imaginando o imaginário. Revista Brasileira de História, São Paulo, v.15, n.29, p.9-27, 1995. Disponível em: $<$ http://www.anpuh.org/revistabrasileira/view?ID_REVISTA_BRASILEIRA=14>. Acesso em: 31 jan. 2014.

SIMMEL, G. Questões fundamentais da Sociologia: indivíduo e sociedade. Rio de Janeiro: Zahar, 2006.

WITTICH, W. A.; SCHULLER, C. F.. Recursos Audiovisuais na Escola. Centro de Publicações Técnicas da Aliança Missão Norte-Americana de Cooperação Econômica e Técnica no Brasil [USAID]. Rio de Janeiro, 1964.

ZAMBONI, E. Representações e linguagens no ensino de História. Revista Brasileira de História, São Paulo, v.18, n.36, p.89-102, 1998. Disponível em: <http://www.scielo.br/scielo.php?pid=S0102-01881998000200005\&script=sci_arttext>. Acesso em: 31 jan. 2014. 